\title{
Subject Met Eligibility Criteria But Was Not Needed
}

National Cancer Institute

\section{Source}

National Cancer Institute. Subject Met Eligibility Criteria But Was Not Needed. NCI

Thesaurus. Code C150884.

An indication that the individual met inclusion and exclusion criteria but was ultimately not utilized as a trial subject. 